\title{
Red cell distribution width's role in differentiating iron deficiency anemia from other hypochromic microcytic anemias
}

Received: 15/ 07/ 2020

Accepted: 25/ 10/ 2020

\author{
Shno I brahim Hussein ${ }^{1 *} \quad$ Abbas Abdulkadir Rabaty ${ }^{2}$
}

\begin{abstract}
Background and objective: The red cell distribution width is suggested to be a more sensitive indicator for microcytic hypochromic anemia. Therefore, this study aimed to determine the role of red cell distribution width in the diagnosis of iron deficiency anemia from other causes of hypochromic microcytic anemia.

Methods: This cross-sectional study involved the children patients who attended Rapareen Teaching Hospital in Erbil city in 2019 and were diagnosed with hypochromic microcytic anemia.

Results: The red cell distribution width was determined in a group of 70 children with iron deficiency anemia and 30 cases with a non-iron deficiency (other hypochromic microcytic anemias). Patients with a higher socio-demographic status were more likely to have iron deficiency anemia than those with low socio-demographic status; $82.61 \%$ vs. $76.60 \%$, respectively. The patients with symptoms were more likely to be diagnosed with iron deficiency anemia $(P=0.024)$. The mean red cell distribution width value was $14.38 \%$, $15.73 \%$, and $18.02 \%$ among mild, moderate, and severely anemic children $(P<0.001)$. Increasing red blood cells $(r=-0.271)$, hemoglobin $(r=-0.454)$, serum iron $(r=-0.601)$, and serum ferritin ( $r=-0.560)$ lead to decrease red cell distribution width. The sensitivity, specificity, positive predictive value, negative predictive value, and accuracy of red cell distribution width in diagnosing iron deficiency anemia in children patients were $77.14 \%$, $63.33 \%, 83.08 \%, 54.29 \%$, and $73.0 \%$, respectively.
\end{abstract}

Conclusions: This study showed that red cell distribution width has good sensitivity and specificity in diagnosing iron deficiency anemia.

Keywords: RDW; IDA; RBC indices; Microcytic anemia; Serum iron.

\section{Introduction}

Red blood cells (RBC) are responsible for hemoglobin levels. Deficits in their production, increased destruction, or loss through bleeding are three main mechanisms by which anemia occurs. ${ }^{1}$ Anemia resulting from a lack of sufficient iron to synthesize hemoglobin is the most common hematological disease in infants and children. It has been estimated that $30 \%$ of the global population suffers from iron deficiency anemia (IDA). ${ }^{2}$ The highest level of hemoglobin is in the first three days of life $(18.5 \mathrm{gm} / \mathrm{dl})$, which decreases gradually until six months of age when it becomes $11.5 \mathrm{gm} / \mathrm{dl}$ then starts to increase again until reaching $12.5 \mathrm{gm} / \mathrm{dl}$ between 2 and 6 years old age. ${ }^{3}$ Anemia in children between 6-59 months old can be divided into mild (10-10.9 $\mathrm{gm} / \mathrm{dl})$, moderate (7-9.9 $\mathrm{gm} / \mathrm{dl})$, and severe $(<7 \mathrm{gm} / \mathrm{dl}){ }^{3,4}$

Iron deficiency is the most commonly seen micronutrient nutritional deficiency among children and has contributed significantly to an increase in morbidity and mortality. The most severe consequence of iron deficiency seen is IDA. ${ }^{5}$ Iron has a vital role in many biologic functions, including energy production, respiration, and cell proliferation. IDA is the end-stage result of the lack of iron in the body resulting from inadequate iron intake, increased iron

${ }^{1}$ Rapareen Pediatric Hospital, Erbil, I raq

2 Department of Pediatrics, College of Medicine, Hawler Medical University, Erbil, I raq.

* Correspondence: shnoibrahim5@gmail.com 
loss, or excessive iron requirements. ${ }^{6}$ As a consequence, erythropoiesis becomes insufficient to fulfill the body's physiologic needs. ${ }^{1}$ Complete blood count (CBC) is used for primary evaluation of anemia. A CBC can help determine the mean corpuscular volume (MCV), which measures the average size of RBCs, and mean corpuscular hemoglobin concentration, which measures the concentration of hemoglobin $(\mathrm{Hb})$ in a given amount of packed RBCs. ${ }^{7}$

Red cell distribution width (RDW) measures the variation in red blood cell volume or red blood size. Its normal range is $12.8 \pm 1.2 \%{ }^{8}$ RDW is suggested to be a more sensitive indicator to establish the possible parameter for microcytic hypochromic anemia. ${ }^{9} \mathrm{RDW}$ can give the idea of early changes in RBC, which is accompanied IDA. ${ }^{10,11}$ It is done as part of $\mathrm{CBC}$. Its value is usually beneficial for several cases such as anemias, especially of microcytic hypochromic types, diabetes mellitus, heart diseases, liver diseases, and cancers. ${ }^{12,13}$ High levels of RDW may indicate a deficiency of nutrients such as folate, vitamin B12, and iron. A normal level of RDW with low MCV may be found in chronic kidney diseases. A normal RDW with high MCV may indicate aplastic anemia. $^{14}$

Various diagnostic approaches are important to rule out diseases with adequate accuracy. Bone marrow studies are invasive methods, and serum ferritin, serum transferrin, and serum iron are relatively expensive. RDW, alongside other red cell indices, are part of routine blood counts in laboratories using automated hematology analyzers. Some of these tests do not have high sensitivity and specificity; therefore, patients have to undergo further evaluation for the diagnosis of IDA. ${ }^{15}$

Several previous studies have reported the controversial role of RDW in the diagnosis of IDA. ${ }^{16,17}$ These studies did not report the conclusive word on using RDW in the diagnosis of IDA. Therefore, this study aimed to determine the role of RDW in the diagnosis of IDA from other causes of hypochromic microcytic anemia.

\section{Methods}

In this cross-sectional study, patients with IDA and non-IDA who attended Rapareen Teaching Hospital in Erbil city were screened physically and clinically for the eligibility criteria. They were referred to the hospital laboratory for investigations.

The included patients were children aged between 1 and 5 years old who were diagnosed with microcytic anemia; IDA, and non-IDA. The following exclusion criteria were applied to the patients; patients who did not complete iron study; children who received iron therapy over the past month, or blood transfusion over the past three months; patients who had an acute infection during data collection; patients with IDA along with concomitant thalassemia trait or disease; and children diagnosed with a chronic disorder, lead poisoning or sideroblastic anemia.

The diagnoses of the anemia types were established for microcytic (MCV <75fl) anemia or hemoglobin $<11 \mathrm{~g} / \mathrm{dL}$; and IDA: serum iron $<25 \mu \mathrm{g} / \mathrm{dL}$ and ferritin $<12 \mathrm{ng} /$ $\mathrm{ml} .{ }^{18}$ Red cell distribution width measures the variation in red blood cell volume (Normal range: $12.8 \pm 1.2 \%) .{ }^{8} \mathrm{An}$ anonymous questionnaire was presented to the patients' patents or accompanied persons who provided the following information. The information was collected in two sections in a pre-designed questionnaire. The questionnaire was composed of three domains: demographic and socioeconomic data, nutritional habits and presenting complaints, and hematological parameters.

Part A- Demographic and socioeconomic data: Part A included general information, including age, weight, gender, residency (urban, rural), socioeconomic state, and clinical presentation. ${ }^{19}$

Part B- Nutritional habits and clinical presentation: This part included the feeding -related information of patients. The information included feeding in the first 
six months categorized as breastfeeding, bottle-feeding, mixed feeding, type of child's current and main feeding, and drinking tea. The current feeding of patients was recorded as ordinary family food, breastfeeding, commercial infant formula, and adult milk feeding. The following sign and symptoms were collected, pallor, loss of appetite, poor weight gain, irritability, and pica.

Part C - hematological parameters: It included the results of medical investigations, including information on $\mathrm{RBC}, \mathrm{HB}, \mathrm{MCV}, \mathrm{MCH}$, serum ferritin, serum iron, and IDA. The patients were determined as microcytic (MCV <75fl) anemia (hemoglobin $<11 \mathrm{~g} / \mathrm{dL}$ ), IDA (serum iron $<25 \mu \mathrm{g} / \mathrm{dL}$ and ferritin $<12 \mathrm{ng} / \mathrm{ml}){ }^{18}$ and RDW (normal range are 12.8 $\pm 1.2 \%)^{8}$. Venous blood samples $(10 \mathrm{~mL})$ were collected using a disposable syringe after 8 to $9 \mathrm{~h}$ of fasting; $4 \mathrm{~mL}$ of blood was placed in a lavender top tube containing EDTA. The automated hematology analyzer (mythic 22- orphee- Geneva/ Switzerland) was used for evaluating complete blood count. Serum ferritin and serum iron level were measured by an automated chemistry analyzer (Roche Cobas C 311- Hitachi Tokyo/ Japan).

The descriptive purposes of the study were determined in number and percentage, including the prevalence of IDA and other hypochromic microcytic anemias, including thalassemia trait or disease, anemia of chronic disorder, lead poisoning, and sideroblastic anemia. The general information was presented in the form of mean and standard deviation (SD) or number and percentage. Independent t-test and one-way ANOVA tests were performed to compare socioeconomic status, feeding patterns, clinical manifestations, and hematological parameters between two groups. The bivariate correlation was performed to find out the correlation of RDW with hematological parameters. The sensitivity and specificity of RDW in the diagnosis of IDA in children were determined in percentage. The significant level was determined in a $P$ value of less than 0.05 . The statistical calculations were performed by the statistical package for the social sciences (SPSS, version 25; IBM Corp; USA).

The ethical approval of the present study was obtained from the ethical committee of the Kurdistan Board of Medical Specialties (KBMS). The confidentiality of the personal information of the patients was protected by the anonymity of participants. The written informed consent was obtained from the patient's parents before participating in the study.

\section{Results}

The mean age and weight of the patients were 2.33 (SD: 1.28 years) and 13.37 (SD: $3.93 \mathrm{Kg})$, respectively. The patients were males $(56.0 \%)$ and females (44.0\%). Most of them live in urban areas $(72.0 \%)$. In the current study, out of 100 blood samples tested, 70 were diagnosed with IDA, and 30 samples were non-iron deficiency. In the socioeconomic status, there was a significant difference between both groups $(P=0.015)$. Thepercentageof IDA was $82.6 \%$ among those with high socioeconomic status (SES), $50 \%$ among those with moderate SES, and $76.6 \%$ among those with low SES, as shown in Table 1.

The highest percentage of IDA was among the breastfeeding group $(79.31 \%)$, and the lowest percentage $(62.5 \%)$ was among the mixed feeding group. In the bottle feeding group, the percentage was more than half $(68.09 \%)$. Statistically, there were no significant differences $(P=0.383)$ in the first six months of feeding. The clinical symptoms of IDA as compared with other hypochromic microcytic anemia were pallor $(100 \%, 83.33 \%)$, loss of appetite $(78.57 \%$, $46.67 \%)$, poor weight $(72.86 \%, 20.00 \%)$, irritability $(25.71 \%, 6.67 \%)$, and pica (35.71\%, 3.33\%), respectively, as revealed in Table 2. 
Red cell distribution width's role in differentiating ...

Zanco J. Med. Sci., Vol. 25, No. (3), December, 2021 https:/ / doi.org/ 10.15218/ zjms.2021.028

Table 1 Types of anemia according to the socioeconomic status and feeding behavior

\begin{tabular}{llcccccc}
\hline $\begin{array}{l}\text { Patient } \\
\text { characteristics (100) }\end{array}$ & Categories & $\begin{array}{c}\text { No of } \\
\text { patients }\end{array}$ & \multicolumn{2}{c}{ IDA } & \multicolumn{4}{c}{$\begin{array}{c}\text { Other } \\
\text { hypochromic } \\
\text { anemia }\end{array}$} & P value \\
& & & No. & (\%) & No. & (\%) & \\
\hline Socioeconomic & Low & 47 & 36 & $(76.60)$ & 11 & $(23.40)$ & $\mathbf{0 . 0 1 5}$ \\
state & Moderate & 30 & 15 & $(50.00)$ & 15 & $(50.00)$ & \\
& High & 23 & 19 & $(82.61)$ & 4 & $(17.39)$ & \\
Feeding & Breastfeeding & 29 & 23 & $(79.31)$ & 6 & $(20.69)$ & 0.383 \\
(First 6 months) & Bottle feeding & 47 & 32 & $(68.09)$ & 15 & $(31.91)$ & \\
& Mixed Feeding & 24 & 15 & $(62.50)$ & 9 & $(37.50)$ & \\
Feeding & Ordinary Family & 64 & 44 & $(68.75)$ & 20 & $(31.25)$ & 0.633 \\
(Current Feeding) & food & & & & & & \\
& Breast Milk & 6 & 4 & $(66.67)$ & 2 & $(33.33)$ & \\
& Commercial & 9 & 8 & $(88.89)$ & 1 & $(11.11)$ & \\
& Infant Formula & & & & & & \\
& Adult Milk & 21 & 14 & $(66.67)$ & 7 & $(33.33)$ & \\
Feeding & No & 58 & 40 & $(68.97)$ & 18 & $(31.03)$ & 0.791 \\
(Drinking Tea) & Yes & 42 & 30 & $(71.43)$ & 12 & $(28.57)$ & \\
\hline
\end{tabular}

Pearson Chi-squared test was performed for statistical analyses.

The bold numbers show a significant association.

Table 2 Comparison of symptoms between patients with iron deficiency anemia and other hypochromic anemias

\begin{tabular}{|c|c|c|c|c|c|}
\hline $\begin{array}{l}\text { Symptoms } \\
\text { Pallor }\end{array}$ & \multicolumn{2}{|c|}{ IDA $(n=70)$} & \multicolumn{2}{|c|}{$\begin{array}{l}\text { Other hypochromic } \\
\text { anemia }(n=30)\end{array}$} & $\begin{array}{l}P \text { value } \\
<0.001\end{array}$ \\
\hline Yes & 70 & 100 & 25 & 83.33 & \\
\hline No & 0 & 0.00 & 5 & 16.67 & \\
\hline Loss of Appetite & & & & & 0.002 \\
\hline Yes & 55 & 78.57 & 14 & 46.67 & \\
\hline No & 15 & 21.43 & 16 & 53.33 & \\
\hline Poor Weight & & & & & $<0.001$ \\
\hline Yes & 51 & 72.86 & 6 & 20.00 & \\
\hline No & 19 & 27.14 & 24 & 80.00 & \\
\hline Irritability & & & & & 0.029 \\
\hline Yes & 18 & 25.71 & 2 & 6.67 & \\
\hline No & 52 & 74.29 & 28 & 93.33 & \\
\hline Pica & & & & & 0.001 \\
\hline Yes & 25 & 35.71 & 1 & 3.33 & \\
\hline No & 45 & 64.29 & 29 & 96.67 & \\
\hline
\end{tabular}

Pearson Chi-squared test was performed for statistical analyses.

The bold numbers show a significant association 
The means of RBC, HB, RDW, MCV, $\mathrm{MCH}$, serum ferritin, and serum iron were 4.59 $10^{\times 12} / \mathrm{L}, \quad 9.41 \mathrm{~g} / \mathrm{dl}, \quad 15.32 \%, 61.03 \mathrm{fl}$, $20.36 \mathrm{pg}, 16.91 \mathrm{ng} / \mathrm{ml}$, and $31.02 \mathrm{mg} / \mathrm{dl}$, respectively. All of the patients included in this study were anemic and microcytic, as shown in Table 3.

In the RDW comparison between IDA and non-IDA groups, the mean RDW scores were significantly higher in the IDA group (16.40) than in the non-IDA group (12.82) in independent t-test $(P<0.001)$. In addition, the RDW means were increasing with the severity of IDA (mild, moderate, and severe anemia were $14.38 \%, 15.73 \%$ and $18.02 \%$, respectively).

The width of red cell distribution was decreased with increasing RBC count $(\mathrm{r}=-0.271 ; \quad P=0.013), \mathrm{Hb} \quad(\mathrm{r}=-0.454$; $P \quad<0.001), \quad \mathrm{MCH} \quad(\mathrm{r}=-0.291, \quad \mathrm{p}=0.008)$, serum iron $(r=-0.601, P<0.001)$, and serum ferritin $(r=-0.560, P<0.001)$, as presented in Table 4.

The sensitivity, specificity, positive predictive value (PPV), negative predictive value (NPV), and accuracy of RDW in the diagnosis of IDA in children patients were $77.14 \%, 63.33 \%, 83.08 \%, 54.29 \%$, and $73.0 \%$, respectively (Table 5 )

Table 3 Hematological parameters of the studied groups

\begin{tabular}{|c|c|c|c|c|}
\hline \multirow[t]{2}{*}{ Parameter $(n=100)$} & \multicolumn{2}{|c|}{ Statistics Mean (SD) } & \multirow[b]{2}{*}{$\begin{array}{l}\text { Other microcytic } \\
\text { anemia }\end{array}$} & \multirow[b]{2}{*}{$P$ value } \\
\hline & All patients & IDA & & \\
\hline RBC count & $4.59(0.62)$ & $4.46(0.61)$ & $4.83(0.69)$ & $0.015^{\mathrm{a}}$ \\
\hline $\mathrm{Hb}$ & $9.41(1.25)$ & $9.10(1.33)$ & $10.10(0.65)$ & $<0.001^{\mathrm{a}}$ \\
\hline PLT count & $335.56(76.27)$ & $340.13(73.18)$ & $324.90(83.35)$ & $0.390^{a}$ \\
\hline $\begin{array}{l}\text { RDW (Normal values: } \\
12.8 \pm 1.2 \%)(\mathrm{CV})\end{array}$ & $15.32(2.44)$ & $16.40(1.91)$ & $12.82(1.53)$ & $<0.001^{a}$ \\
\hline MCV & $61.03(5.42)$ & $60.42(5.85)$ & $62.36(4.09)$ & $0.066^{\mathrm{a}}$ \\
\hline $\mathrm{MCH}$ & $20.36(2.07)$ & $19.84(2.08)$ & $21.48(1.55)$ & $<0.001^{a}$ \\
\hline Serum ferritin & $16.91(15.22)$ & $7.67(2.74)$ & $39.21(8.00)$ & $<0.001^{a}$ \\
\hline Serum iron & $31.02(24.24)$ & $16.29(4.59)$ & $65.40(14.47)$ & $<0.001^{a}$ \\
\hline \multicolumn{5}{|c|}{ RDW category (IDA group) } \\
\hline Mild & & $14.38(2.38)$ & & $<0.001^{b}$ \\
\hline Moderate & & $15.73(2.16)$ & & \\
\hline Severe & & $18.02(0.71)$ & & \\
\hline
\end{tabular}

${ }^{a}$ An independent t-test and ${ }^{b}$ ANOVA one-way were performed for statistical analyses.

Table 4 Correlation of RDW with hematological parameters

\begin{tabular}{llcccccc}
\hline & \multicolumn{9}{c}{ Correlations } \\
& & RBC & HB & MCV & MCH & S.iron & S.ferritin \\
\hline \multirow{2}{*}{ RDW } & The correlation coefficient $(r)$ & -0.271 & -0.454 & -0.136 & -0.291 & -0.601 & -0.560 \\
& P-Value & $\mathbf{0 . 0 1 3}$ & $<0.001$ & 0.221 & $\mathbf{0 . 0 0 8}$ & $<0.001$ & $<0.001$ \\
\hline
\end{tabular}

Table 5 Sensitivity and specificity of RDW in the diagnosis of IDA in children

\begin{tabular}{cccccccccc}
\hline & TP & TN & FP & FN & Sensitivity & Specificity & PPV & NPV & Accuracy \\
\hline RDW & 54 & 19 & 11 & 16 & $77.14 \%$ & $63.33 \%$ & $83.08 \%$ & $54.29 \%$ & $73.0 \%$ \\
\hline
\end{tabular}

TP: True positive; TN: True negative; FP: False positive; and FN: False negative

PPV: Positive predictive value; NPV: negative predictive value 


\section{Discussion}

Values of RDW are one of the RBC indices that reflect the degree of anisocytosis of red blood cells. It has been used to differentiate between patients with IDA and thalassemia trait for decades. ${ }^{20}$ In the present study, $70 \%$ were diagnosed with IDA, and $30 \%$ of samples with non-iron deficiency. This agreed with a study conducted in India, ${ }^{21}$ which showed that out of 100 cases, $79 \%$ were found to have IDA, and $21 \%$ were non-iron deficient anemia. The results above showed a significant difference in a low socioeconomic state between IDA and other hypochromic microcytic anemia $(76.60 \%$ and $23.40 \%)$, respectively. This is comparable to the previous studies, ${ }^{20,22}$ which revealed a protective effect of high IDA prevalence in a representative pediatric population in Korea and India. The onset of IDA can be affected by several factors, which include age, sex, physiological, pathological, and nutritional state. However, illiteracy and low standard of living are the main causes of anemia among children. The clinical features of IDA and hypochromic microcytic anemia are similar to those of other types of anemia, although there are specific symptoms attributed to iron deficiency. These agreed with Llanos et al. and Wang, who reported that iron imbalance in IDA is affected by several mechanisms, which included reduced absorption, increased losses, and/or increased requirements. Often such factors can coexist, requiring complex management of the consequent anemia. $^{23,24}$ Also, Fareeq documented a positive effect of IDA on physical growth in children, especially during the first two years of life during which growth is fast. ${ }^{25}$

The means of RDW in IDA and other microcytic anemia were 16.40 and 12.82 , respectively. These agreed with two other studies that showed overall average RDW value of $18.31 \pm 1.75$ and $17.3 \pm 2.5$ in IDA, respectively. ${ }^{16,26}$ It was stated that RDW is useful in the early detection of IDA. Also, our result has good sensitivity, specificity, and predictive values in the diagnosis of
IDA in children. The width of red cell distribution was decreased with increasing $\mathrm{RBC}, \mathrm{Hb}, \mathrm{MCH}$, serum iron, and serum ferritin. This agreed with Jassim, who documented that RBC count, Hb, Hct, $\mathrm{MCH}$, and $\mathrm{MCHC}$ were significantly lower, whereas RDW was significantly higher in IDA subjects. ${ }^{27}$ Similarly, the RDW means were increased with the severity of IDA. This result was concordant with Choudhary et al. in that there was a progressive increase in RDW with the severity of anemia, and there was also a progressive decrease in MCV with an increase in the severity of anemia. ${ }^{5}$ In addition, another study reported the inverse association between RDW and the hemoglobin value in the IDA group. However, this kind of association was not found in the control group. ${ }^{17}$ Similar findings were reported in other studies. ${ }^{9,20,28-31}$ It has been seen that anisocytosis occurs, where the erythrocytes produced are of smaller than average size and have a large size variation due to inadequate iron supply. The morphology and function of erythrocytes at a molecular level have been known to be disturbed due to IDA. Therefore, an increase in RDW values may occur in IDA, allowing early detection of ID before the reduction in MCV occurs. ${ }^{28}$

The evaluation of microcytic anemias and/ or microcytosis is an expensive process. To differentiate these diseases from each other, a set of investigations is required. Complete blood counts, serum iron, serum ferritin, TIBC, $\mathrm{Hb}$ electrophoresis are performed for the definitive diagnosis. ${ }^{5,15,29}$ The RBC indices are cost-effective parameters to detect anemias. ${ }^{30}$ However, in patients with microcytic anemias, RBC shows similar results, such as low hemoglobin and MCV. Red cell distribution width is a better index than RBC to differentiate IDA from other causes of microcytosis; since it is abnormal in the development of IDA. $^{31}$ Similar findings were reported elsewhere. ${ }^{20,32}$ 


\section{Conclusion}

RDW can be used as a tool for the diagnosis of IDA in a large number of samples at major hospitals to reduce time consumption because of the high prevalence of IDA and expensive costs of specialized tests and adopting costeffective, accurate and efficient measures is required. Red cell distribution width has good sensitivity and specificity for IDA screening diagnosis amongst patients with the hypochromic microcytic anemia.

\section{Funding}

None.

\section{Competing interests}

None declared.

\section{References}

1. Burz C, Cismaru A, Pop V, Bojan A. IronDeficiency Anemia. London: Intech Open; 2018. https://doi.org/10.5772/intechopen.80940.

2. Vehapoglu A, Ozgurhan G, Demir AD, Uzuner S, Nursoy MA, Turkmen S, et al. Hematological Indices $f$ or Differential Diagnosis of Beta Thalassemia Trait and Iron Deficiency Anemia. Anemia. 2014; 2014:576738. https://doi.org/10.1155/2014/576738.

3. World Health Organization. Haemoglobin concentrations for the diagnosis of anaemia and assessment of severity; 2011. World Health Organization. https://apps.who.int/iris/handle/ 10665/85839.

4. Abdul-Fatah BN, Murshid RM, Ahmed TE. Assessment of iron deficiency anemia (IDA) and dietary pattern among pregnant women in Baghdad city, Iraq. J Pharm Sci Res. 2018; 10(9):2279-84.

5. Choudhary M, Sharma D, Shekhawat DS, Dabi D. Significance of red cell distribution width in the diagnosis of iron deficiency anemia: An observational study from India. J Pediatr Neonatal Care. 2015; 3(1):00102. https://doi.org/10.15406/ipnc.2015.02.00102.

6. Miller JL. Iron deficiency anemia: A common and curable disease. Cold Spring Harbor Lab Press 2013; 3(7):a011866. https://doi.org/ 10.1101\%2Fcshperspect.a011866.

7. Mogahed MM. Abdelwahab SM. Early prediction of iron deficiency in females in child bearing age in central Saudi Arabia. Alexandria Journal of Medicine. 2019; 54:561-6. https://doi.org/10.1016/ j.ajme.2017.11.010.

8. Bates I. Reference ranges and normal values. In: Bain BJ, Bates I, Laffan MA, editors. Dacie and Lewis Practical Haematology. Elsevier;
2017. PP8-17. https://doi.org/10.1016/B978-07020-6696-2.00002-3.

8. Purnamasidhi CAW, Suega K, Bakta M. Role of red cell distribution width (RDW) in the diagnosis of iron deficiency anemia. Indonesia J Biomed Sci. 2019; 13(1):12-15. http://dx.doi.org/10.15562/ijbs.v13i1.160.

9. Sultana GS, Haque SA, Sultana T, Ahmed AN. Value of red cell distribution width (RDW) and RBC indices in the detection of iron deficiency anemia. Mymensingh Med J. 2013; 22(2):370-6.

10. Sultana GS, Haque SA, Nessa A, Muttalib MA, Rahman Q. Red Cell Distribution Width (RDW) and $\mathrm{Hb} \%$ in the Detection of Iron Deficiency Anemia in Pregnant Women. AKMMC J. 2018; 9(2):137-41. https://doi.org/10.3329/ akmmcj.v9i2.39210.

11. Xanthopoulos N, Giamouzis G, Melidonis A, Kitai T, Paraskevopoulou E, Paraskevopoulou P, et al. Red blood cell distribution width as a prognostic marker in patients with heart failure and diabetes mellitus. Cardiovascular Diabetology. 2017; 16:81. https://doi.org/10.1186/s12933-0170563-1

12. $\mathrm{Li} \mathrm{Y}$, Xing $\mathrm{CH}$, Wei $\mathrm{M}$, Wu $\mathrm{H}, \mathrm{Hu} \mathrm{X}$, $\mathrm{Li} S$, et al. Combining Red Blood Cell Distribution Width (RDW-CV) and CEA Predict Poor Prognosis for Survival Outcomes in Colorectal Cancer. J Cancer. 2019; 10(5):116270. https://doi.org/10.7150/jca.29018.

13. Salvagno GL, Sanchis-Gomar F, Picanza A, Lipp G. Red blood cell distribution width: A simple parameter with multiple clinical applications. Crit Rev Clin Lab Sci. 2014; 52(2):86-105. https://doi.org/10.3109/10408363.2014.992064.

14. Aulakh R, Sohi I, Singh T, Kakkar N. Red Cell Distribution Width (RDW) in the Diagnosis of Iron Deficiency with Microcytic Hypochromic Anemia. Indian J Pediatr. 2009; 76:265-8. https://doi.org/10.1007/s12098-009-0014-4.

15. Dugdale AE, BadrickT. Red blood cell distribution width (RDW)- a mechanism for normal variation and changes in pathological states. J Lab Precis Med. 2018; 3:73. https://doi.org/10.21037/jlpm.2018.08.03.

16. Benie T. Red Cell Distribution Width, Revisited. Lab Medicine. 2013; 44(2):e2-9. https://doi.org/10.1309/LMZ1GKY9LQTVFBL7.

17. United Nations. World Health Organization, Iron Deficiency Anaemia: Assesment, Prevention and Control: a Guide for Programme Managers; 2001. World Health Organization.

18. Omer W, Al-Hadithi T. Developing a socioeconomic index for health research in Iraq. East Mediterr Health J. 2017; 23(10):670-7. https://doi.org/10.26719/2017.23.10.670.

19. Aslan D, Gümrük $F$, Gürgey $A$, Altay $C$. Importance of RDW value in differential diagnosis of hypochromeanemias. Am J Hematol. 2002; 69(1):31-3. https://doi.org/10.1002/ajh.10011. 
20. Sharma A, Sharma M, Sharma V. Evaluation of red cell distribution width in the diagnosis of iron deficiency anemia. Int J Res Med Sci. 2016; 4(9):3733-6. http://dx.doi.org/10.18203/23206012.ijrms20162603.

21. Bharati S, Pal M, Chakrabarty S, Bharati P. Socioeconomic determinants of iron-deficiency anemia among children aged 6 to 59 months in India. Asia Pac J Public Health. 2015; 27(2):NP1432-43. https://doi.org/10.1177\% 2F1010539513491417.

22. Llanos G, José M, Zamudio G, José L, de los L, Reyes-García MJ. Significance of anaemia in the different stages of life. Enfermería Global. 2016; 15(3):419-30. https://doi.org/10.6018/ eglobal.15.3.248221.

23. Wang M. Iron deficiency and other types of anemia in infants and children. American Family Physician. 2016; 93(4):270-8.

24. Fareeq $\mathrm{ZH}$, Zangana KO. Influence of iron deficiency anemia on growth: A cross-sectional study. Med J Babylon. 2019; 16(4):335-40.

25. Kamila KH, Mohammad NS. A laboratory study of anemia in children aged 6 months to 6 years in Erbil city. Babylon J. 2014; 11(2):274-84.

26. Jassim AN. Comparative behavior of red blood cells indices in iron deficiency anemia and $\beta$-thalassemia trait. Iraqi Journal of Hematology. 2016; 5(2):183-6.

27. Zhanga $Y$, Zhang W, WangaSh, Wanga C, Xiea $J$, Chen $X$, et al. Detection of human erythrocytes influenced by iron deficiency anemia and thalassemia using atomic force microscopy. Micron. 2012; 43(12):1287-92. https://doi.org/10.1016/j.micron.2011.10.018.

28. Sirachainan N, lamsirirak $P$, Charoenkwan $P$, Kadegasem $P$, Wongwerawattanakoon $P$, Sasanakul W, et al. New mathematical formula for differentiating thalassemia trait and iron deficiency anemia in thalassemia prevalent area: a study in healthy school-age children. Southeast Asian J Trop Med Public Health. 2014; 45(1):174-82.

29. Nadeem R, Ahmed N, Qureshi GR. Automated measurement of red blood cell microcytosis and hypochromia in iron deficiency and beta thalassemia trait. PJMHS. 2012; 6(1):20-3.

30. Santosh S, Kushal KK, Ramesh AC. A study on red cell distribution width in relation to other iron (red cell) indices with special reference to reticulocyte count before and after oral iron therapy in iron deficiency anemia. Int J Basic Appl Med Sci. 2013; 3(1): 292-9.

31. Qureshi NA, Chauhan MAZ, Goswami AP, Suri SK. Study of anemia and its correlation with Hematological parameters in patient of various age group. J Dent Med Sci. 2015; 14(9):29-35. https://doi.org/10.9790/0853-14942935. 